\title{
Linolenic acid and folate in wild-growing African dark leafy vegetables (morogo)
}

\author{
Anna M van der Walt ${ }^{1} *$, Mohamed IM Ibrahim ${ }^{1}$, Cornelius $C$ Bezuidenhout $^{1}$ and \\ Du Toit Loots ${ }^{2}$ \\ ${ }^{1}$ School of Environmental Sciences and Development, North-West University (Potchefstroom Campus), Private \\ Bag X6001, Potchefstroom 2531, South Africa: ${ }^{2}$ School of Physiology, Nutrition and Consumer Sciences, \\ North-West University (Potchefstroom Campus), Potchefstroom, South Africa
}

Submitted 12 April 2007: Accepted 12 March 2008: First published online 27 May 2008

\begin{abstract}
Background: Transition from a low-fat vegetable-rich rural diet to a high-fat Westernised diet is considered a factor in the escalating occurrence of vascularrelated diseases and type 2 diabetes in urban black South Africans. Consumption of morogo is a distinguishing feature of rural African diets.

Objective: To determine fatty acid profiles and folate contents of three widely consumed, wild-growing, African dark green leafy vegetables (morogo).

Design: GC-MS was applied for analysis of fatty acid composition and a validated microbiological assay conducted to determine folic acid contents of wild-growing morogo sampled from deep rural villages in three different geographical regions of South Africa.

Results: Measured fatty acids ranged from $1610 \cdot 2$ to $2941.6 \mathrm{mg} / 100 \mathrm{~g}$ dry mass, with PUFA concentrations $1 \cdot 4$ to $2 \cdot 8$ times those of SFA. Calculated from the relative percentages of linoleic acid $(18: 2 n-6)$ and linolenic acid $(18: 3 n-3)$, the ratio of $18: 2 n-6$ to $18: 3 n-3$ PUFA was $1 \cdot 0: 3 \cdot 4$ to $1 \cdot 0: 8 \cdot 9$. The only MUFA was palmitoleic acid (16:1), measured at $34 \cdot 7$ (sD 0.3) to $79 \cdot 0(\mathrm{sD} 9 \cdot 3) \mathrm{mg} / 100 \mathrm{~g}$ dry mass, and the predominant SFA was palmitic acid (16:0), measured at $420 \cdot 6$ (SD $83 \cdot 3$ ) to $662 \cdot 0(\mathrm{sD} 21 \cdot 2) \mathrm{mg} / 100 \mathrm{~g}$ dry mass. Folic acid concentration varied from 72 to $217 \mu \mathrm{g} / 100 \mathrm{~g}$ fresh sample.

Conclusion: Morogo is low-fat food item high in folate and with $18: 3 n-3$ in excess of $18: 2 n-6$, the proposed anti-inflammatory effects of which may lower risks of vascular-related chronic diseases and type 2 diabetes.
\end{abstract}

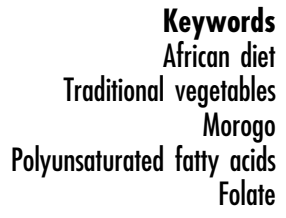

Chronic lifestyle-related cardio- and cerebrovascular diseases (CVD) and type 2 diabetes are becoming more pronounced in urbanised black South Africans ${ }^{(1)}$. Levitt and Mollentze ${ }^{(2)}$ predicted that type 2 diabetes could affect over 3 million South Africans by 2010. The occurrence of these lifestyle-related chronic diseases apparently does not discriminate on a socio-economic basis ${ }^{(1,3,4)}$. Currently, dietary transition from a traditional low-fat, plant protein-rich rural diet towards a high-fat, animal protein-rich Westernised diet receives much attention as a factor contributing to the increased occurrence of chronic diseases of lifestyle in urbanised black South Africans ${ }^{(5,6)}$. In rural diets, a variety of cultivated and/or wild-growing African dark green leafy vegetables (morogo) supplement traditional maize-based staples $^{(7)}$. Concerning micronutrient levels, morogo vegetables compare well with spinach, Swiss chard and cabbage ${ }^{(8-10)}$. Dark green leafy vegetables (DGLV) are also indicated as rich sources of folate ${ }^{(11,12)}$ and linolenic acid $(18: 3 n-3)^{(13-15)}$. Nutritional data on cultivated varieties of traditional African vegetables are fragmentary and almost non-existent for wild-growing morogo species. The present study reports on the fatty acid profiles and folate contents of three wild-growing morogo species: cowpea (munawa), vegetable amaranth (thepe) and spider flower (lerotho; also known as African cabbage or cat's whiskers).

\section{Materials and methods}

\section{Sample collection and preparation}

Sampling sites were situated in three geographically separated and climatically distinct areas of South Africa. One fresh field sample of each morogo type, i.e. amaranth, spider flower and leafy cowpea, were collected from rural villages respectively in the Rustenburg District (North-West Province), as well as Vhembe and Capricorn Districts (Limpopo Province). One traditionally sun-dried, household sample of spider flower was obtained from 
a rural family in Capricorn District. Samples were transported to the laboratory in Ziploc ${ }^{\circledR}$ plastic bags on ice. Upon arrival at the laboratory, the fresh samples were freeze-dried and stored at $-20^{\circ} \mathrm{C}$ until analysis. Finely ground, freeze-dried sample material and the traditionally sun-dried material were subsequently used for fatty acid analysis. Samples for folic acid determinations were weighed accurately before oven-drying at $105^{\circ} \mathrm{C}$ for approximately $1 \mathrm{~h}$ until oven-dried weight remained constant. Moisture loss was recorded for use as a dry to wet mass conversion factor in calculations of folate concentrations in fresh leaves.

\section{Chemicals}

All organic solvents used were of GC grade and, together with fatty acid standards, were purchased from SigmaAldrich Corp. (St. Louis, MO, USA).

\section{Folic acid analysis}

Freeze-dried morogo samples were sent to the South African Bureau of Standards (Pretoria, South Africa) for folic acid analysis. A standard method for the microbiological assay of folic acid in foods and pharmaceutical products was employed ${ }^{(16,17)}$. Streptococcus faecalis (ATCC 8043; American Type Culture Collection, Manassas, VA, USA) was the test organism. Materials included USP folic acid standard (Merck, Darmstadt, Germany), Difco Bacto-folic AOAC medium (code 0967; Becton Dickinson Microbiology Systems, Sparks, NV, USA) and Oxoid MRS agar (code CM 361; Oxoid Ltd, Basingstoke, UK) as culture media; and Oxoid MRS agar (code CM 359; Oxoid Ltd) to prepare the inoculum. Folic acid detection limit was $0 \cdot 0005 \mu \mathrm{g} / \mathrm{ml}$. Dry mass concentrations were converted for expression as $\mu \mathrm{g} / 100 \mathrm{~g}$ wet mass.

\section{Fatty acid determinations}

Heptadecanoic acid (72 mm), as an internal standard, was added to $25 \mathrm{mg}$ of lyophilised sample followed by $100 \mu \mathrm{l}$ of a $45 \mathrm{~mm}$ solution of butylated hydroxytoluene and $2 \mathrm{ml}$ of methanolic $\mathrm{HCl}(3 \mathrm{M})$. The mixture was subsequently vortexed before incubation at $90^{\circ} \mathrm{C}$ for $4 \mathrm{~h}$. Following cooling to room temperature, the sample was extracted twice with $2 \mathrm{ml}$ of hexane, dried under an $\mathrm{N}_{2}$ stream and finally re-suspended in $100 \mu \mathrm{l}$ of hexane, $1 \mu \mathrm{l}$ of which was injected into the GC-MS system via split-less injection. An Agilent 6890 gas chromatograph ported to a 5973 mass selective detector (CA, USA) was used for identification and quantification of individual fatty acids. For the acquisition of an electron ionisation mass spectrum, an ion source temperature of $200^{\circ} \mathrm{C}$ and electron energy of $70 \mathrm{eV}$ were used. The gas chromatograph was equipped with a SE-30 capillary column (Agilent, Palo Alto, CA, USA), a split/split-less injection piece $\left(250^{\circ} \mathrm{C}\right)$ and a direct GC-MS coupling $\left(260^{\circ} \mathrm{C}\right)$. Helium $(1 \mathrm{ml} / \mathrm{min})$ was used as the carrier gas. An initial oven temperature of $50^{\circ} \mathrm{C}$ was maintained for $1.5 \mathrm{~min}$ and then allowed to increase to $190^{\circ} \mathrm{C}$ at a rate of $30^{\circ} \mathrm{C} / \mathrm{min}$. The oven temperature was maintained at $190^{\circ} \mathrm{C}$ for $5 \mathrm{~min}$ and then allowed to increase at a rate of $8^{\circ} \mathrm{C} / \mathrm{min}$ to $220^{\circ} \mathrm{C}$, this temperature being maintained for $2 \mathrm{~min}$. Finally, ramped at a rate of $3^{\circ} \mathrm{C} / \mathrm{min}$, the oven temperature was maintained at $230^{\circ} \mathrm{C}$ for $24 \mathrm{~min}$. All samples were analysed in triplicate and reported as the mean and standard deviation of concentration in $\mathrm{mg} / 100 \mathrm{~g}$.

\section{Statistical analyses}

Data of fatty acid analyses were processed using the STATISTICA Data Analysis Software System version $7 \cdot 1$ (StatSoft, Inc., Tulsa, OK, USA). Statistical evaluation of measured folic acid concentrations employed statistical techniques included in a computerised data processing program of the South African Bureau of Standards.

\section{Results}

\section{Botanical species identification}

Amaranth (thepe) samples were identified as Amaranthus bybridus L. subsp. cruentus (L.) Thell. (Rustenburg), Amaranthus bybridus L. subsp. bybridus var bybridus (Vhembe) and Amaranthus thunbergii Moq. (Capricorn). Spider flower (lerotho) from Rustenburg and Capricorn were in both instances identified as Cleome gynandra L. and cowpea (munawa) as Vigna unguiculata (L.) Walp. subsp. unguiculata (Table 1).

\section{Folate contents}

Results of the folic acid determinations (Table 1) indicated considerable variation in folic acid concentrations in

Table 1 Folic acid contents and botanical species identification of wild-growing amaranth, spider flower and cowpea: sampling sites were situated in three geographically separated and climatically distinct areas of South Africa (Rustenburg District, North-West Province; Vhembe and Capricorn Districts, Limpopo Province)

\begin{tabular}{|c|c|c|}
\hline Plant species & Study area & $\begin{array}{c}\text { Folic acid content } \\
(\mu \mathrm{g} / 100 \mathrm{~g} \text { fresh sample) }\end{array}$ \\
\hline Amaranthus hybridus L. subsp. cruentus (L.) Thell. (amaranth/thepe) & Rustenburg & 72 \\
\hline Amaranthus hybridus L. subsp. hybridus var hybridus (amaranth/thepe) & Vhembe & 122 \\
\hline Amaranthus thunbergii Moq. (amaranth/thepe) & Capricorn & 130 \\
\hline Cleome gynandra L. (spider flower/lerotho) & Capricorn & 217 \\
\hline Vigna unguiculata (L.) Walp. subsp. unguiculata (cowpea/munawa/dinawa) & Vhembe & 154 \\
\hline
\end{tabular}


morogo: $217 \mu \mathrm{g} / 100 \mathrm{~g}$ fresh weight (spider flower, Capricorn), $154 \mu \mathrm{g} / 100 \mathrm{~g}$ fresh weight (leafy cowpea, Vhembe), $122 \mu \mathrm{g} / 100 \mathrm{~g}$ fresh weight (amaranth, Vhembe), $130 \mu \mathrm{g} /$ $100 \mathrm{~g}$ fresh weight (amaranth, Capricorn) and $72 \mu \mathrm{g} / 100 \mathrm{~g}$ fresh weight (amaranth, Rustenburg).

\section{Fatty acid profiles}

Total measured fatty acid concentrations (Table 2) ranged from $1610 \cdot 2 \mathrm{mg} / 100 \mathrm{~g}$ dry mass in Capricorn amaranth to as high as $2941.6 \mathrm{mg} / 100 \mathrm{~g}$ dry mass in spider flower of Rustenburg. The major PUFA detected in all samples included linolenic acid (18:3n-3), ranging from $753 \cdot 8$ (SD $48 \cdot 6$ ) to $1629 \cdot 7$ (sD $77 \cdot 1) \mathrm{mg} / 100 \mathrm{~g}$ dry mass, and linoleic acid $(18: 2 n-6)$, ranging from $110 \cdot 8$ (sD $7 \cdot 1)$ to $506 \cdot 3$ (sD $47 \cdot 2) \mathrm{mg} / 100 \mathrm{~g}$ dry mass. Palmitic acid (16:0), the predominant SFA, varied between $420 \cdot 6$ (SD 83.2) and $662 \cdot 0(\mathrm{sD} 21 \cdot 2) \mathrm{mg} / 100 \mathrm{~g}$ dry mass and the only MUFA, palmitoleic acid $(16: 1)$, ranged between $34 \cdot 7$ (SD $0 \cdot 3$ ) and $79 \cdot 0$ (SD 9.3) $\mathrm{mg} / 100 \mathrm{~g}$ dry mass. Table 3 indicates the relative percentages of SFA and PUFA in terms of the total measured fatty acid concentrations. The ratio of SFA to PUFA ranged from $1 \cdot 0: 1 \cdot 4$ to as high as $1 \cdot 0: 2 \cdot 8$, and PUFA contents from $51.5 \%$ (Vhembe amaranth) to $73.5 \%$ (Vhembe cowpea leaves). Notable variations were observed in measured concentrations of both $18: 2 n-6$ and $18: 3 n-3$ in samples of the same plant genus but from different species or different localities. The highest dry mass concentrations of PUFA (Table 2) were found for Rustenburg samples of amaranth and spider flower, with values for $18: 2 n-6$ of $506 \cdot 3$ (SD $47 \cdot 2$ ) and $385 \cdot 7$ (SD 9.7) $\mathrm{mg} / 100 \mathrm{~g}$ dry mass, respectively and for $18: 3 n-3$ of 1183.9 (SD 114.9) and $1554 \cdot 3$ (sD 59.4) $\mathrm{mg} / 100 \mathrm{~g}$ dry mass, respectively. Expressed in percentages of total measured fatty acids (Table 3), ratios of $18: 2 n-6$ to $18: 3 n-3$ PUFA in Vhembe amaranth (1:9), spider flower (1:4.5) and Rustenburg amaranth and Vhembe cowpea leaves (1:3.4) were in favour of $18: 3 n-3$ PUFA.

\section{Discussion}

Steyn ${ }^{(6)}$ describes the low-fat, plant protein-rich diet of rural black South Africans as most prudent. Wild-growing DGLV, such as amaranth, spider flower and cowpea, feature prominently in this type of $\operatorname{diet}^{(7,18)}$. DGLV are important sources of food folate ${ }^{(11,12)}$. Table 1 shows that folic acid concentrations of amaranth varied between 72 and $130 \mu \mathrm{g} / 100 \mathrm{~g}$ fresh weight, while its concentration was $217 \mu \mathrm{g} / 100 \mathrm{~g}$ fresh weight in spider flower and $154 \mu \mathrm{g} / 100 \mathrm{~g}$ fresh weight in cowpea. South African food composition data (SAFCOD) tables ${ }^{(10)}$ report the folic acid concentrations in raw samples of these vegetables respectively as 64,346 and $141 \mu \mathrm{g} / 100 \mathrm{~g}$ fresh weight. The folic acid concentrations in raw leaves of other morogo vegetables such as amadumbe, black jack and nightshade $^{(7)}$ are respectively 126,351 and $404 \mu \mathrm{g} / 100 \mathrm{~g}$ fresh

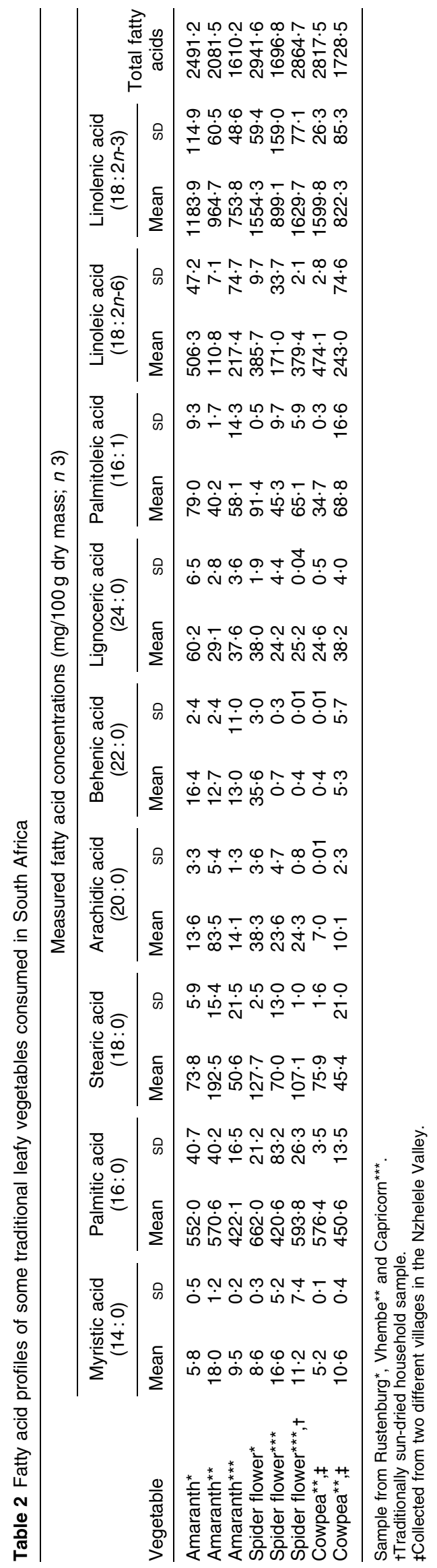




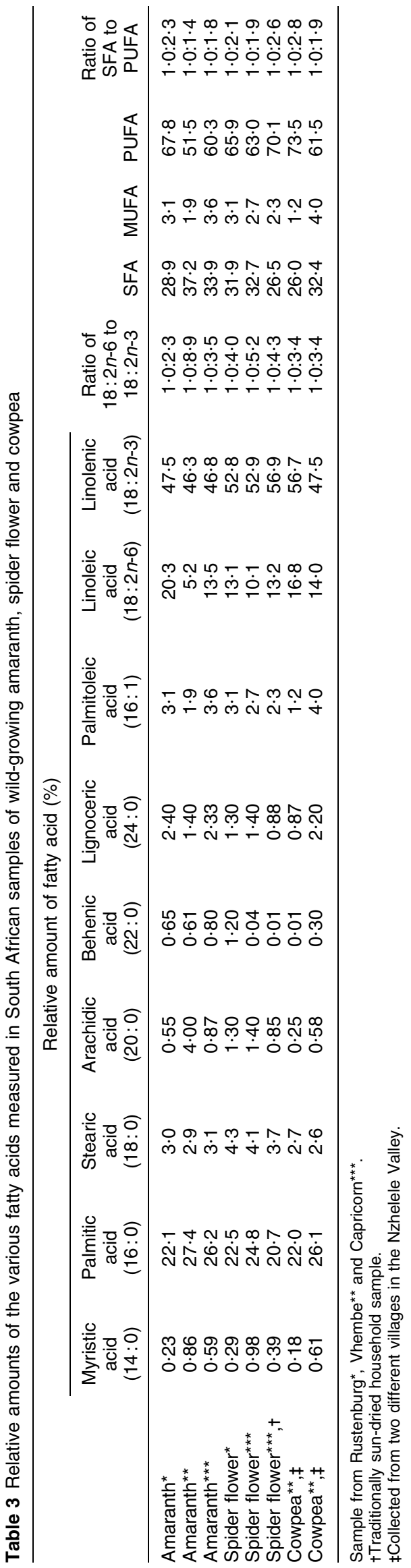

weight and that of raw commercial Swiss chard, $52 \mu \mathrm{g} / 100 \mathrm{~g}$ fresh weight ${ }^{(10)}$. Boiled amaranth contains $5 \mu \mathrm{g}$ folic acid/ $100 \mathrm{~g}$ fresh weight, cowpea leaves $60 \mu \mathrm{g} / 100 \mathrm{~g}$, sweet potato leaves (also consumed as morogo) $124 \mu \mathrm{g} / 100 \mathrm{~g}$ and commercial spinach $146 \mu \mathrm{g} / 100 \mathrm{~g}^{(10)}$. Values reported from the National Food Consumption Survey for the percentage of energy derived from plant and animal sources $^{(19)}$ indicate that rural populations in South Africa consume a larger amount of plant foods than their urban contemporaries. Families in the Mopani District of Limpopo Province indicated that, when available, morogo is eaten on a daily basis ${ }^{(20)}$. Results from the present study and information provided by the SAFCOD tables ${ }^{(10)}$ suggest that, if consumed on a regular basis in normal amounts, morogo vegetables could be an important source of dietary folate.

In addition, DGLV generally contain small amounts of fat predominantly in the form of PUFA ${ }^{(10)}$. In the present study, six SFA, one MUFA and two PUFA (18:2n-6 and $18: 3 n-3)$ featured in differing ratios in the fatty acid profiles of the three types of morogo (Table 2). In all samples, 16:0 was the predominant SFA measured in concentrations higher than $18: 2 n-6$ but lower than $27 \%$ of $18: 3 n-3$. The ratio of SFA to PUFA in wild-growing morogo vegetables ranged from $1 \cdot 0: 1 \cdot 4$ to $1 \cdot 0: 2 \cdot 8$ (Table 3 ). Calculated from the SAFCOD tables ${ }^{(10)}$ the ratios of SFA to PUFA in other morogo and commercial vegetables are of

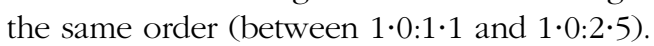

The following percentages of energy from total fat are indicated for various groups of adult black South African males ${ }^{(6,21)}$ : rural areas $22 \cdot 9 \%$; informal settlements $24.3 \%$; urban middle class $26 \cdot 0 \%$; urban upper class $30 \cdot 6 \%$. Steyn et $a l^{(22)}$ found that a rural black population derived $3 \cdot 7-4 \cdot 4 \%$ of energy from SFA compared with $8 \cdot 5-9 \cdot 2 \%$ for an urban black population. The following consumption pattern is indicated for black South Africans in terms of the percentage of the population consuming a food item respectively in rural and urban settings ${ }^{(6)}$ : meat 46 and $74 \%$; full cream milk and products 10 and $60 \%$; vegetable fats and oils 26 and $62 \%$. The adoption of a Westernised diet due to urbanisation $^{(5,21)}$ appears to be linked with a propensity among black South Africans to consume greater amounts of fat. Moreover, the fat content of their diet seems to increase with the degree of affluence. Simopoulos ${ }^{(23)}$ describes the Western diet as 'deficient' in 18:3n-3 mainly because of the high intakes of cereals and vegetable oils rich in $18: 2 n-6$ and the low intakes of fruits, nuts and DGLV containing large amounts of $18: 3 n-3$. Sanders ${ }^{(24)}$ maintains that, consumed in normal amounts, DGLV would contribute little to the dietary intake of $18: 3 n$ - 3 because of the overall low fat content. In rural settings, morogo vegetables are prepared mixed with other plant foods, including groundnuts and traditional legumes such as cowpeas, which are expected to contribute to the overall $18: 3 n-3$ intake $(7,10,20,23,25)$. 
Adequacy in dietary $18: 3 n-3$ is essential for the biosynthesis of DHA, the long-chain PUFA derivative with vital membrane, brain and cardiac functions ${ }^{(14,24)}$. In all the morogo vegetables $18: 3 n-3$ was the predominant PUFA with ratios of $18: 2 n-6$ to $18: 3 n-3$ ranging between $1 \cdot 0: 2 \cdot 3$ to $1 \cdot 0: 8 \cdot 9$ (Table 3). EPA, an intermediate in the synthesis of DHA, and DHA are both absent from plant foods and very low in ruminant fats such as milk and dairy products ${ }^{(14)}$. Since the synthesis of DHA from $18: 3 n-3$ via EPA occurs at a slow rate in man, EPA and DHA sufficiency is dependent on dietary intake from sources such as oily fish and seafood $^{(14)}$. With limited access to oily fish and seafood, poultry and eggs would serve as an alternative, though less efficient, source of EPA and DHA, provided animals are not fed on grain concentrates high in $18: 2 n-6$ which competitively inhibits the conversion of EPA to DHA ${ }^{(14)}$. Dietary studies in South Africa indicate the following relevant consumption pattern in rural and urban black South Africans, respectively ${ }^{(6)}$ : grain-based food (maize porridge, sorghum and bread) 98.6 and $98.5 \%$; fish (canned) 3.2 and $10 \cdot 6 \%$; eggs and egg products $7 \cdot 4$ and $16 \cdot 2 \%$; vegetables $48 \cdot 1$ and $42 \cdot 8 \%$. Rural and urban black South Africans thus have equally high $18: 2 n-6$ intakes from grain staples, and seem to derive EPA and DHA primarily from poultry, eggs and canned fish. However, raised on commercial corn mixtures, poultry and eggs purchased from urban retail outlets are expected to have a higher $18: 2 n-6$ content $^{(23,24)}$ than similar items consumed by rural farm-based families. Furthermore, the percentage of urban black South Africans consuming vegetable fats and oils is $2 \cdot 4$ times the rural subjects $^{(6)}$, implying a higher overall 18:2n-6 intake by urban populations. Rural populations furthermore consume a wider range of vegetables, including DGLV (morogo) which is absent from the vegetable list of their urban contemporaries ${ }^{(6)}$.

By comparison, urban black South Africans seem more likely to consume a diet high in SFA and 18:2n-6 and lower in folate than rural families in subsistence settings. This dietary trend could relate to findings of epidemiological studies suggesting that the high fat content of their Westernised diet might be a prominent factor in the rise of Western lifestyle diseases in urbanised black South Africans ${ }^{(1,2,26,27)}$. Notwithstanding underlying genetic factors, obesity in black populations is attributed to overnutrition and linked with the consumption of a Westernised diet ${ }^{(26,28)}$. In conjunction with other negative factors (e.g. excessive alcohol use, cigarette smoking and a sedentary lifestyle) obesity enhances risks of chronic diseases among adults ${ }^{(6,21,27,29)}$. Biological functions of long-chain fatty acids respectively derived from $18: 2 n-6$ and $18: 3 n-3$ differentially modulate risks of $\mathrm{CVD}^{(12,15,23)}$, degenerative and inflammatory diseases ${ }^{(14,30)}$ as well as type 2 diabetes ${ }^{(31)}$. Proposed antioxidant and antiinflammatory actions of folate ${ }^{(12)}$ may further enhance the health protective value of morogo consumption. In combination with tetrahydrobiopterin and insulin, folate suppresses superoxide anion generation and increases endothelial nitric oxide and prostacyclin production, both of which are potent platelet anti-aggregators and vasodilators ${ }^{(30)}$. The inhibiting effect exerted by dietary $18: 3 n-3$ intake on the clotting activity of platelets ${ }^{(32)}$ appears to act complementary to mechanisms by which folate lowers risks of CVD. Mandatory folic acid fortification of various food items, and national strategies aimed at increasing fruit and vegetable intake and reducing saturated fat consumption in Western countries, emphasise the importance of folate and $18: 3 n-3$ in disease prevention ${ }^{(12,33)}$.

The present study underscores the value of morogo vegetables as low-fat food items that could contribute notable amounts of folate and provide $18: 3 n-3$ in excess of $18: 2 n-6$. Lowering fat intakes and including morogo vegetables could adjust the diet of urbanised black South Africans to a more prudent one. Reporting the health beneficial qualities of morogo could improve the image of these valuable vegetables and enhance their marketability in wider society and urban centres. Future research should focus on expanding the nutritional database, including possible anti-nutritional properties. Epidemiological studies could accurately assess the role of morogo vegetables in health and disease.

\section{Acknowledgements}

The Morogo Research Programme (MRP) gratefully acknowledges the National Research Foundation of South Africa (NRF) for financial support of this study (Focus Area Grant FA2004050600064), the South African National Botanical Institute for botanical species identification, and Mrs Mary Blythe (South African Bureau of Standards, Pretoria) for folic acid analysis of morogo samples and statistical evaluation of results. The MRP is most grateful to the communities in Vhembe, Capricorn and Phokeng for allowing sampling of their morogo.

Conflict of interest: The corresponding author hereby states that there is no 'conflict of interest' concerning the data published in the present paper. The study was carried out as a part of the corresponding author's PhD research. Analysis was funded by the NRF Focus Area Grant (FA2004050600064) to the corresponding author. The present article is included as a chapter in the $\mathrm{PhD}$ thesis entitled 'Fusarium in rural subsistence agro-environments of traditional African green leafy vegetables and consumer health aspects - an ecological approach'. The thesis clearly indicates Public Health Nutrition as the scientific journal publishing this article.

Author contributions: A.M.v.d.W. was the grant holder of the NRF Focus Area Grant (FA2004050600064) funding the present research; and contributed to project design and coordination, interpretation of the results and writing of the article. M.I.M.I. carried out sample extraction and execution of analytical procedures. C.C.B. 
supervised the $\mathrm{PhD}$ project and contributed to interpretation of the results. D.T.L. supervised the analytical procedures and data processing.

\section{References}

1. Vorster HH (2002) The emergence of cardiovascular disease during urbanisation of Africans. Public Health Nutr 5, 239-243.

2. Levitt N \& Mollentze WF (1995) Diabetes and impaired glucose tolerance: a review of South African studies. In Chronic Diseases of Lifestyle in South Africa, pp. 109-121 [J Fourie and K Steyn, editors]. MRC Technical Report. Tygerberg: Medical Research Council.

3. Panz VR \& Joffe BI (1999) Impact of HIV infection and AIDS on prevalence of type 2 diabetes in South Africa in 2010. BMJ 318, 1351-1352.

4. Van der Merwe M-T, Crowther NJ, Schlaphoff GP, Gray IP, Joffe BI \& Lönnroth PN (2000) Evidence for insulin resistance in black women from South Africa. Int $J$ Obes Relat Metab Disord 24, 1340-1346.

5. Bourne LT, Lambert E \& Steyn K (2002) Where does the black population of South Africa stand on the nutrition transition? Public Health Nutr 5, 157-162.

6. Steyn N (2006) Nutrition and chronic diseases of lifestyle in South Africa. In Nutrition and Chronic Diseases of Lifestyle in South Africa: 1995-2005, pp. 33-47 [K Steyn, J Fourie and N Temple, editors]. MRC Technical Report. Tygerberg: Medical Research Council.

7. Jansen van Rensburg WS, Van Averbeke W, Slabbert R, Faber M, Van Jaarsveld P, Van Heerden I, Wenhold F \& Oelofse A (2007) African leafy vegetables in South Africa. Water SA 33, 317-326.

8. Odhav B, Beekrum S, Akula U \& Baijnat H (2006) Preliminary assessment of nutritional value of traditional leafy vegetables in KwaZulu-Natal, South Africa. J Food Compost Anal 20, 430-435.

9. Mnkeni AP, Masika P \& Maphaha M (2007) Nutritional quality of vegetable and seed from different accessions of Amaranthus in South Africa. Water SA 33, 377-380.

10. Kruger M, Sayed N, Langenhoven M \& Holing F (1998) Composition of South African Foods. Vegetables and Fruit. Tygerberg: Medical Research Council.

11. Kalter H (2000) Folic acid and human malformation: a summary and evaluation. Reprod Toxicol 14, 463-476.

12. Das UN (2003) Folic acid says NO to vascular disease. Nutrition 19, 686-692.

13. Singh RB, Pella D, Mechirova V \& Otsuka K (2004) Can brain dysfunction be a predisposing factor for metabolic syndrome? Biomed Pharmacother 58, S56-S68.

14. Innis SM (2007) Dietary ( $n$-3) fatty acids in brain development. J Nutr 137, 855-859.

15. Simopoulos AP (1991) Omega-3 fatty acids in health and disease and in growth and development. Am J Clin Nutr 54, 438-463.

16. Association of Official Analytical Chemists (1999) Folic acid. In Official Methods of Analysis, 16th ed. Washington, DC: Association of Official Analytical Chemists.
17. Barton-Wright EC (1961) Practical Methods for the Microbiological Assay of the Vitamin B-complex and Amino Acids. London: United Trade Press.

18. Schippers RR (2002) African Indigenous Vegetables: An Overview of the Cultivated Species, revised ed. Chatham, UK: Natural Sources Institute.

19. Labadarios D, Steyn NP, Maunder E et al. (2005) The National Food Consumption Survey (NFCS): South Africa, 1999. Public Health Nutr 8, 533-543.

20. Van der Walt AM, Mossanda KSA, Jivan SD, Swart WJ \& Bezuidenhout CC (2005) Indigenous African food plants: vehicles of disease or sources of protection? Indilinga $\mathbf{4}$, 279-279.

21. Bourne L \& Steyn K (2000) Rural/urban nutrition-related differentials among adult ethnic groups in South Africa, with special emphasis on the black population. S Afr J Clin Nutr 13, S23-S28.

22. Steyn NP, Burger S, Monyeki KD, Alberts M \& Nthangeni G (2001) Seasonal variation in dietary intake of the adult population of Dikgale. S Afr J Clin Nutr 14, 140-145.

23. Simopoulos AP (2001) Evolutionary aspects of diet, essential fatty acids and cardiovascular disease. Eur Heart J3, Suppl. D, D8-D21.

24. Sanders TAB (1999) Essential fatty acid requirements of vegetarians in pregnancy, lactation, and infancy. Am J Clin Nutr 70, Suppl. 3, 555S-559S.

25. Faber M, Van Jaarsveld PJ \& Laubscher R (2007) The contribution of dark-green leafy vegetables to total micronutrient intake of two- to five-year-old children in a rural setting. Water SA 33, 407-412.

26. Van Rooyen JM, Kruger HS, Huisamen HW, Wissing MP, Margetts BM, Venter CS \& Vorster HH (2000) An epidemiological study of hypertension and its determinants in a population in transition: the THUSA study. J Hum Hypertens 14, 779-787.

27. Vorster HH, Wissing MP, Venter CS et al. (2000) The impact of urbanisation on physical, physiological and mental health on Africans in the North West Province of South Africa: the THUSA study. S Afr J Sci 96, $505-513$.

28. Joffe BI \& Seftel HC (1994) Diabetes mellitus in the black communities of Southern Africa. J Intern Med 235, $137-142$

29. Puoane T, Steyn K, Bradshaw D, Laubscher R, Fourie J, Lambert V \& Mbananga N (2002) Obesity in South Africa: the South African demographic and health survey. Obes Res 10, 1038-1048.

30. Lombardo YB \& Chicco AG (2006) Effects of dietary polyunsaturated $n-3$ fatty acids on dyslipidemia and insulin resistance in rodents and humans. A review. J Nutr Biochem 17, 1-13.

31. Suresh Y \& Das UN (2003) Long-chain polyunsaturated fatty acids and chemically-induced diabetes mellitus: effect of $\omega$-3 fatty acids. Nutrition 19, 213-228.

32. Renaud S, Godsey F, Dumont E, Thevenon C, Ortchanian E \& Martin JL (1986) Influence of long-term diet modification on platelet function and composition in Moselle farmers. Am J Clin Nutr 43, 136-150.

33. Mills JL (2000) Fortification of foods with folic acid - how much is enough? New Engl J Med 342, 1442-1445. 